\title{
E-learning in Iran as a developing Country: Challenges Ahead and Possible Solutions
}

\author{
Mas`oud Mahmoodi-Shahrebabaki, Massoud Yaghoubi-Notash (PhD) \\ University of Teheran, Faculty of Foreign Languages and Literatures, Teheran, Iran \\ masoud.mahmoodi@outlook.com
}

University of Tabriz, English Department, Faculty of Persian Literature \& Foreign Languages, Tabriz, Iran

masoud.yaghoubi@gmail.com

\begin{abstract}
E-learning has lately grown into a proliferating area because of its good potentials for instructional and assessment purposes. Context of instruction where e-learning is commissioned can bear implications for the scope and instances of application. The present study addresses the major challenges faced in this respect by Iranian practitioners and also offer some practical solutions to these challenges. As a descriptive study in nature, the data population comprised 350 Iranian citizens from various social, economical and educational backgrounds aged between 16 and 53 who were asked to prioritize six major challenges Iranian people face regarding the e-learning arena on a standardized Likert-type scale. The challenges were selected from among those earlier cited in the related literature. Six major challenges to be prioritized were: lack of government support, lack of public awareness, high costs of e-learning, collectivist society of Iran, low-speed internet, internal filtering and external sanctions. The results indicated that lack of public awareness, lack of government support and collectivist society of Iran were chosen by the participants as the main hurdles in the path of e-learning development in Iran, respectively. Further solutions and implications of the study are discussed in the study.
\end{abstract}

\section{Indexing terms/Key words:}

E-learning, Challenges in E-learning, E-learning in Iran

\section{Academic Discipline and Sub-Disciplines}

Education, educational technology

\section{Subject Classification}

E-learning

\section{Council for Innovative Research}

\section{Peer Review Research Publishing System}

Journal: INTERNATIONAL JOURNAL OF RESEARCH IN EDUCATION METHODOLOGY

Vol 6, No.2

www.jjrem.com, ijremeditor@gmail.com 


\section{INTRODUCTION}

Very few aspects, if at all, of our modern-day routines seem to have remained uninfluenced by computer, the twentieth century wonder machine. Irresistible and hard to escape as they may appear, these sweeping changes have also promised new potentials for various fields and activities including education. E-learning as a rapidly growing, if not to say a volatile, field can offer a wide range of potentials for research and practice (Fryer, Bovee, \& Nakao, 2014). Therefore elearning can possibly bear a good deal of potentials for instructional theorizing, research and practice (see Warshauer \& Liau, 2010 for instance).

E-learning can simply denote the use of electronic devices in education. Rosenberg (2001) limits e-learning to the use of online learning via World Web as "the use of internet technologies to deliver a broad array of solutions that enhance knowledge and performance ... [ [which] is based upon three fundamental criteria: networked, delivered and focus on the broadest view of learning" (p. 28). Nevertheless, not all characterizations of e-learning are confined to that scope. Other definitions expand the realm of e-learning beyond the internet to embrace the computer itself. Generally speaking, elearning can refer to distant electronic learning relying on a wide set of applications and processes, such as

- $\quad$ using internet websites and computers,

- $\quad$ holding virtual classrooms

- delivery of information via internet,

- intranet/extranet networks,

- audio- and videotapes,

- satellite broadcasting,

- interactive televisions,

- CD-ROM, DVD-ROM, and

- tablets and smart phones.

In its early days, e-learning was not very warmly welcomed, as many people thought bringing computers and other voluminous electronic devices into the classroom would marginalize the basically human element. However, as time has passed and technology has worked its way into almost all corners of our personal and social lives including mobile phones, tablets and similar user-friendly, handy devices in the classroom and other educational settings. Nowadays, various interactive designs and applications can be used to minimize distance, cut down on expenses, and boost learner participation while maintaining the quality of instruction thanks to computer as an efficient delivery medium. Institutions in developing countries often face problems keeping up with the rapid pace of developments in technology. Challenges and changes offered by such a technology can be the theme of research studies in various contexts.

\section{LITERATURE ON E-LEARNING}

It is generally suggested in literature that e-learning should conform to requirements of structure, learner characteristics, contextual factors, and attitude as a key factor. Liaw (2004), for example, proposed three requirements for an e-learning environment to be effective, namely, a) learner characteristics, b) instructional structure, and c) interaction. As Passerini \& Granger (2000) put it, e-learning must take into account the learners' affective characteristics, including attitudes, motivation, self-confidence, etc. An analysis of cross-cultural studies conducted in the 1990s showed that changes in attitudes of learners can be more important than enhancement of instructors' expertise in using technological equipment for teaching (Albirini, 2006). Liaw (2002) asserted that a multidisciplinary approach should be taken in order to study learners and teachers' attitude towards e-learning and e-teaching.

Measurement, as a crucial dimension of e-learning, has attracted the attention of authorities in the field. It is generally believed that it should include different aspects of user attitudes to make a useful diagnostic instrument (Wang, 2003). Liaw (ibid) proposed three major measurements for gauging user attitudes toward computer and Internet technologies: affective, cognitive, and behavioral. Perceived enjoyment and perceived self-efficacy are examples of affective and cognitive facets, respectively. Finally, a behavioral intention to use e-learning as a teaching or learning tool can be an example of behavioral aspect (see Liaw \& Huang, 2003).

Integrating technology in educational settings is, in fact, a multi-faceted issue determined by underlying pedagogical theories, curricular requirements, and the acceptance of Information and Communication Technology (ICT) in society as a whole (Granger, Morbey, Lotherington, Owston, \& Wideman, 2002). The literature on instructional technology shows that resorting to web-based education may serve to motivate students and teachers, increase student participation and willingness to communicate, and make learners more self-regulated, independent and self-monitored (Claudia, Steil, \& Todesco, 2004). Multimedia instruction has been proved to augment cognitive skills of learners including their capacity of logical reasoning, problem-solving, analytical reasoning, sustained attention, critical thinking plus visual and audio processing. (Spiro, Feltovich, Jacobson, \& Coulson, 1995). Finally, e-learning environments offer group interaction, such as student to student, or student to teacher. Group interaction is defined as a kind of cooperativelearning that helps learners to make progress through their zone of proximal developmentby the activities which interest them (De Marsico, Sterbini, \& Temperini, 2013; Saba\& Shearer,1994).Using ICT without a solid theory may result in waste of investment and later determent.

Andersson and Grounlund (2009) overviewed and analyzed several studies regarding e-learning implementation and development in several developing countries They discussed challenges of distance education in developing countries and listed 30 challenges and summarize them in four main categories: courses, individuals, technology and context. They asserted that "the overall conclusion of these challenges are equally valid for both developed and developing countries; 
however in developing countries more papers focus on access to technology and context whereas in developed countries more papers concern individuals"( Andersson \& Grounlund, 2009). Umrani-Khan and lyer (2009) consider four determinants of e-learning acceptance as performance expectancy, effort expectancy, social influence and facilitating conditions. According to Henry and Abala (2009), it is estimated that about two million students are not studying in their home country and this figure is estimated to reach up to eight million by 2025. Emergence of internet and recent developments in Open Source Software resulted in rapid growth of distance education. In most of developing countries, in which educational programs heavily depend on governmental support to get the infrastructure and investment, private institutional support plays a crucial role in the expansion of e-learning and e-teaching programs (Lubis 2009). Many developing countries look to Information Technology (IT) as a means of ameliorating the quality of services and reducing employee redundancy (Omidnia, Masrom \& Selamat, 2011).

Mahdizadeh, Biemans, and Mulder (2007) found that teachers' use of e-learning environments can be accounted for to a high extent by their perceptions of the added value of these environments, which in turn are substantially influenced by their opinions about web-based activities and computer-assisted learning. Some studies zeroed in on barriers to using technology in education in general (Muir-Herzig, 2004). Findings have shown that barriers include lack of teacher time, weak technological infrastructure, lack of motivation or theory for technology use and low level expertise of staff. (MuirHerzig, 2004). The time needed by instructors to learn how to use the new technology comprises the time the teacher needs to learn how to work with computers effectively as a personal tool plus gaining competence in using computers as an instructional tool (ibid).

\section{E-learning in Iran}

Iranian ministry of research and science established Payam Noor University in 1988 with the aim of which was offering distance education and part-time degree programs. The decision proved to be fruitful as it paved the way for many subsequent similar programs offered at other higher education institutes in Iran. In fact, "history of e-learning in Iran at present time does not exceed more than 10 years, yet from a realistic point of view we might say that e-based learning in Iran has had an eight year experience and even younger" (Yaghoubi, Malek Mohammadi, Iravani, Attaran and Gheidi, p. 2) (2008). In 1991 distance education program was placed on the agenda of University of Tehran. The university started to offer nine courses to incoming students and newly matriculated students. In about the meantime, Iranian ministry of research and science and technology (MSRT) declared that the first virtual university would be founded accredited by the Ministry as a non-profit institution (Tabatabaei, 2010). Despite all the effort, time and energy, as well as the contributions from both private and governmental sectors, e-learning and e-teaching in Iran are still at their initial stages of development and there are only a few accredited online programs available. Amirkabir University of Technology, Iran University of Science and Technology, Shiraz virtual University and some Islamic virtual colleges and centers like Islamic virtual centers and Faculty of the Science of Hadith offer accredited online academic programs. (Yaghoubi et al. 2008).

E-learning can be seen as a tool for extending the scope of higher education, especially to geographically remote places and underprivileged rural areas. However, the challenges of virtual learning continue to persist. Three main challenges according to Tabatabaei (2010) are a) learners' avoidance of individualized autonomous learning, b) existence of lessons mnemonic with long text, and c) lack of appropriate telecommunications infrastructure. With the technology proceeding rapidly, virtual learning is tracing a more or less difficult path of development. In this study, based on the findings of other previous related studies (Andersoon \& Gronlund, 2009, Kousha, 2004;Mahdizadeh et al., 2008; Omidinia et al., 2011; Rabiee et al., 2012;Tabatabaei, 2010; Yaghoubi et al., 2008), six major challenges in the path of e-learning development in Iran are hypothesized. Although these can be the main obstacles impeding development of e-learning and e-teaching in any other developing country, the context and participants of this study make it more applicable to the Iranian society. Significance of this study lies in the fact that the participants are from different walks of life and this can give a universal picture of e-learning and e-teaching challenges in the eyes of Iranian society.

\section{METHODOLOGY}

Participants of this study are 350 individuals aged between 16 and 53 . Sixty-eight of the participants were BA and MA students of some universities across Tehran. Their field of study was not related to Information Technology or Computer Sciences. Forty-nine of the participants were teachers working in primary schools or secondary schools, 11 of them were retired. Fifty-three were drivers of public transfer vehicles. Forty-two were university professors whose field of study was not related to Information Technology and Computer Sciences. Forty-nine were high-school students. Forty-two were members of staff working in both private and public offices. Forty-seven were people working in the market including salespeople, merchants and brokers. The rationale behind not selecting participants whose field of study is related to Information Technology and Computer Sciences is that due to their familiarity with the issue and their educational or vocational background, their responses might be subject to personal bias. The data for this study was gathered by means of a questionnaire.

A priority Likert-type scale was distributed among 350 participants. Cronbach Alpha of 0.78 was obtained as the internal consistency of the scale. The questionnaire includedthree major components:
(a) demographic information,
(b) computer and Internet experience, and
(c) priority Likert-type scale. 
The parts of the questionnaire are as follows:

Demographic information: The demographic component covered gender, age, education and profession.

Computer and Internet experience: In this component, participants were asked to indicate whetherthey had experience using the Internet, computers and if they have experience using e-learning.

Likert-scale: There were six options in the questionnaire. The six options were the hypothesized challenges of e-learning in Iran. They were asked to prioritize the options in level of importance. The questionnaire was in Persian. They had to put a number in front of each option. For each priority the following scores were considered:

\section{Table 1. Priority Scores Based on Priority Likert-scale}

\begin{tabular}{|c|c|c|}
\hline Priority & Number & score \\
\hline Highest & 1 & 6 \\
\hline High & 2 & 5 \\
\hline Medium & 3 & 4 \\
\hline Low & 4 & 3 \\
\hline Lowest & 5 & 2 \\
\hline Not aPriority & 6 & 1 \\
\hline
\end{tabular}

If one option was not prioritized in the questionnaire, it would be given a 0 score. The total score of each option is the criterion for the level of importance in the eyes of our participants.

\section{FINDINGS}

Seven questionnaires were not considered for analysis because they had repetitive options twice or more. We analyzed 343 questionnaires and we obtained the data as follows:

Table 2. Priority Option Selection Frequency

\begin{tabular}{|c|c|c|c|c|c|c|c|}
\cline { 2 - 7 } \multicolumn{1}{c|}{} & \multicolumn{7}{c|}{$\begin{array}{c}\text { Number of times an option was selected } \\
\text { as the related priority }\end{array}$} \\
\hline $\begin{array}{c}\text { Priority } \\
\text { Option }\end{array}$ & 1 & 2 & 3 & 4 & 5 & 6 & $\begin{array}{c}\text { final } \\
\text { score }\end{array}$ \\
\hline LGS & $121^{*}$ & 105 & 64 & 17 & 3 & 0 & 1564 \\
\hline LPA & 172 & 74 & 67 & 3 & 0 & 0 & 1679 \\
\hline HC & 8 & 14 & 31 & 42 & 28 & 5 & 429 \\
\hline CSI & 32 & 109 & 123 & 42 & 0 & 1 & 1356 \\
\hline LSI & 3 & 30 & 18 & 37 & 21 & 22 & 415 \\
\hline IF \& ES & 7 & 11 & 21 & 26 & 54 & 2 & 369 \\
\hline
\end{tabular}

LGS = Lack of governmental support; LPA = Lack of Public Awareness; HC = High costs of e-learning; CSI = Collective Society of Iran; LSI = Low speed Internet; IF \& EF = internal filtering \& external sanctions

*The number 121, for example, shows that the option 'lack of government support' has been selected 121 times as the first priority. 
The results are shown more simply in the following column chart:

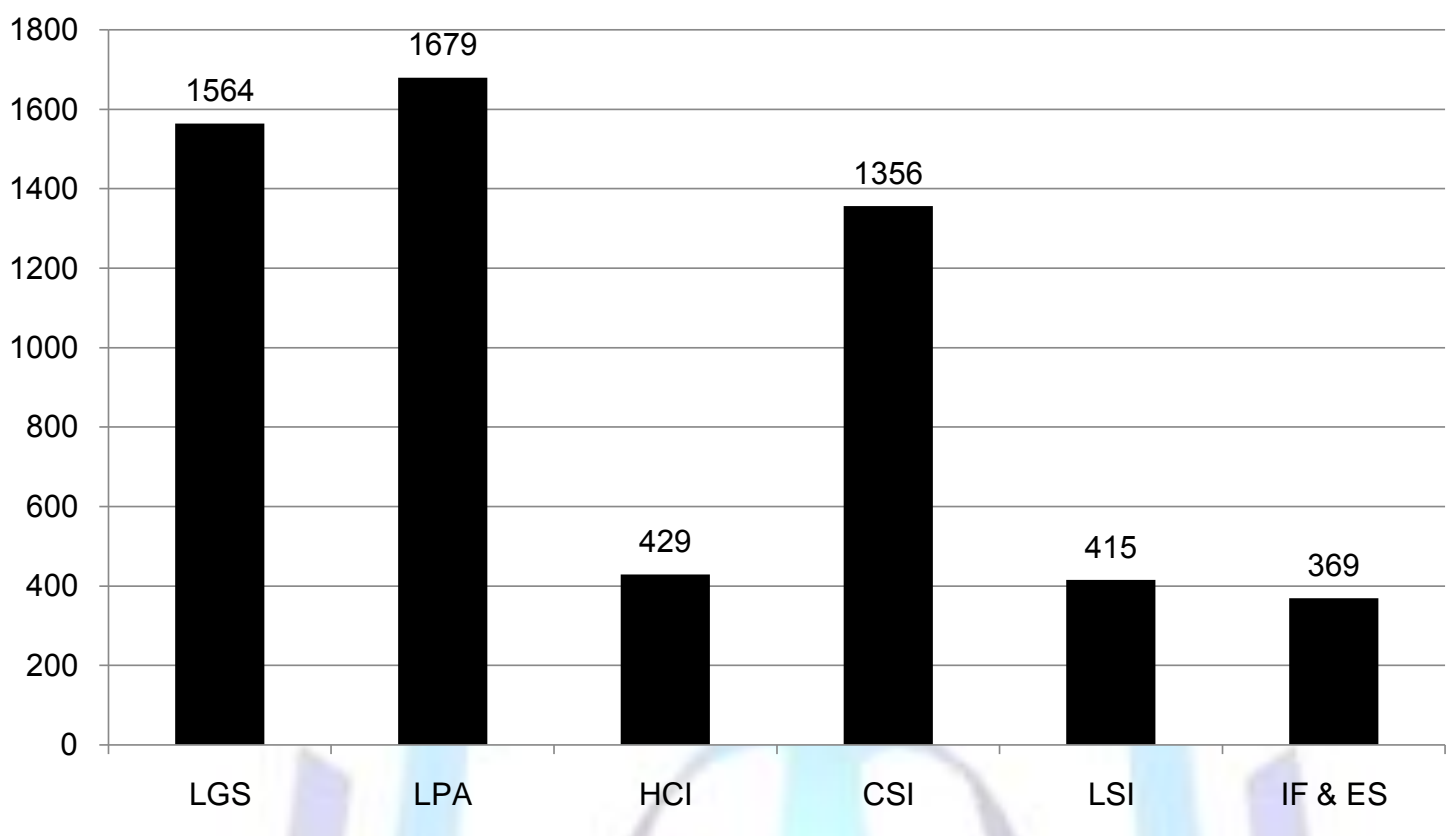

LGS = Lack of governmental support; LPA = Lack of Public Awareness; HC = High costs of e-learning; CSI = Collective Society of Iran; LSI = Low speed Internet; IF \& EF = internal filtering \& external sanctions

Figure 1. The overall option scores

As it is obvious from the above column chart lack of public awareness, lack of government support and collectivist society of Iran are mentioned, by our participants, as the main challenges of e-learning and e-teaching in Iran. There is a significant gap between these three options and the other ones.

\section{DISCUSSION AND CONCLUSION}

\section{Government Support and Costs of E-learning}

Infrastructure of development and advancement of any country is to a great extent reliant on the optimality of the educational system of that country. Considering the fact that Iran is a developing country, especial attention to this issue seems to be indispensable. Developed countries around the world are moving towards more use of internet and multimedia devices in any practice of life including learning and teaching. Iran, as a developing country, must keep up with the latest trends in education arena; however, because e-learning and e-teaching are in their infancy in Iran, government should allocate enough funds in three areas of: educating specialized people, advertisements and spread of electronic devices in public schools and universities. The government can help online training courses be offered to students with no fees in public universities (Rabee, Nazarian \& Gharibshaeian, 2013). The credibility of the academic documents of elearning courses is under question from higher official organizations in Iran. So, necessary action should be taken by the Ministry of Sciences and Research in order to give the same credit to e-learning courses as other on-campus courses. Another problem lies in the high costs of e-learning. Multimedia devices must be provided to all public schools and public universities freely. The tuition fees for online programs must be lowered. Free educational DVDs and books about elearning and its benefits may be distributed among different types of people, especially primary school students.

\section{Internet Issues}

Low-speed internet has discouraged many e-learners and e-teachers in Iran. Because e-learning is firstly based on transfer of information, slow connections would not provide e-learners and e-teachers with desirable circumstances to teach or learn. The content of an online course is the same as what is presented in on-campus classes, but the method of delivery is not the same; instead of being physically present in all on-campus sessions, students "take the course as an asynchronous learning experience which means learning from anywhere at anytime using your own computer" (Arsham, 2003). Instruction can be delivered using variety of applications and tools such as Web pages, e-mail, and video conference. By doing this,students have the chance to participate in discussion forums and be actively involved in communicative interactions. They are encouraged to raise questions and to respond to one another. Arsham(2003) explains that "the instructors also have online office hours, during which they will be in their offices and available by phone, fax, and for live discussion in the forum; the instructors also arrange a Student Orientation session, during which they learn how to study effectively and efficiently for the Web-based courses, prior to taking their course"(Arsham, 2003). To succeed in a Web-based course, students should be motivated, and autonomous. If the speed of internet is low, there might be disruptions in all the aforementioned processes. Another issue is concerned with filtering some useful websites mistakenly. These websites must be accessible to all people. If there is inappropriate content in some websites, suitable 
content such as educational videos may be downloaded and distributed by the officials. The last issue is about tough sanctions that make many useful websites inaccessible to Iranian internet users. Some replacement for these websites and their content can be considered by managers of online programs.

\section{Increasing Public Awareness}

Perhaps the main reason why people in Iran are not optimistic about e-learning is that they are not really aware of the benefits and advantages of e-learning and e-teaching. Using internet for doing daily practices saves plenty of time, energy and money. It is recommended that online training courses be available to students from the very early stages, possibly from primary school; this results in students' familiarity with online training and might lead to public acceptance of virtua learning (Rabee et al., 2013). A course about e-learning and e-teaching can be offered in primary schools. Teachers can be encouraged to make more use of e-mail for receiving homework and giving feedback.

\section{Collectivism in Iranian Society}

The comparison of individualism and collectivism deals with how individuals lead their social lives; whether they think of themselves more as individuals or they think collectively as members of communities which they are members of (Rudenstam, 2012). "Individualist" describes someone who is in pursuit of his/her own goals with little or no respect for goals of other groups including his/her family, workmates, community and so on. A collectivist person, on the other hand puts the goals of their superordinate group ahead of his/her goals and ambitions. An individual who is rather individualistic normally prioritize individual ambitions to a higher level and endeavors to realize such ambitions disregarding what is best for the goal of the social institution which they are somewhat related to (Rudenstam, 2012). The mostly cited definition of self-directed learning comes from Knowles who defined it as "a process inwhich individuals take the initiative, with or without the help of others, in diagnosing their learning needs,formulating learning goals, identifying human and material resources for learning, choosing and implementing appropriate learning strategies, and evaluating learning outcomes" (Knowles, 1975). Consider learning process in an individualistic society. In such societies, a person finds himself/herself responsible for learning. He/she does not need much external motivation for learning because he is to learn something in pursuit of his or her personal goals and ambitions. The modern view of education is individualistic, enabling individuals in making their own decisions about their private and public lives and take the full responsibility for their own education. (Arsham, 2012). Thus, individualism is completely in line with e-learning because in an individualistic society the people hold themselves responsible for their own learning. They rely less on a traditional class with other peers around themselves and also an authority called 'teacher' as a source of power and knowledge. The Hofstede Center has put Iran in the category of collectivist societies (Hofstede, 2001). In a collectivist society like Iran, it is difficult to make intrinsic motivation for learners and make them responsible for their own progress in learning. By introducing e-learning to students from the beginning years of their school, they learn to mostly rely on themselves as far as their learning is concerned.

In general, all spheres of our modern life are impacted by computers and digital technologies. That can be a medium as well as a context for e-learning and e-teaching. Alongside cost-effectivess and minimizing the physical distance, and many instructional benefits, e-learning and teaching can provide a degree of equal opportunities in bridging the socio-economic gap. On the other hand, socialization in the learned community as a primary goal of education can be more readily facilitated by the rich arena for sharing knowledge that is provided by the computers, internet, and virtual learning space. E-learning also allows students to reflect on the content of their learning materials and their responses to them allowing them to work at their own pace, regardless of race, sex, disability or appearance, that is to say, democratically (see Richardson \& Swan, 2003). At the very least, these learning potentials can complement to traditional on-campus instruction for higher education candidates in a) providing distance learning (learning off-campus), b) a blended learning/teaching approach (using face-to-face and technology), and/or c) giving variety to educational activities

Making a scholarly use of electronic and computer-based technological developments appears to be highly context sensitive. Particularly in developing countries with many nation-wide social, economical, and educational ventures on the governmental agenda, e-learning is expected to be facing problems and challenges. (see Issa, Hussain, \& Albahadilli, 2009 for instance). All these contribute to an unsteady profile of e-learning in contexts such as Iran. The present study has come up with just three inhibiting factors, namely lack of governmental support, lack of public awareness and collectivist society of Iran. All three factors fit in the broad category of social cultural issues that are typically experienced by most developing countries.

Further studies can shed light on the nature of the challenges by an in-depth examination of

- administrative shortcomings,

- non-supportive fiscal policies,

- limited access to the state-of-the-art hardware and software packages

- public misjudgments about the efficacy of technology in education,

- $\quad$ persistence of traditional views and perspectives,

- resistance from conservative educationalists,

- unqualified personnel, and

- lack of pre-planning 


\section{REFERENCES}

1. Adrich, C. 2004. Simulations and the Future of Learning. San Francisco: Pfeiffer.

2. Albirini, A. 2006. Teachers' attitudes toward information and communication technologies: the case of Syrian EFL teachers. Computersand Education, 47, 373-398.

3. Andersson, A. and Gronlund, A. 2009. A conceptual framework for e-learning in developing countries: A critical review of research challenges. Electronic Journal of Information. System, 38, 1-16.

4. Arsham, H. 2002. Impact of the internet on learning and teaching, Journal of the United States Distance Learning Education. Retrieved September 2013 from http://www.usdla.org/html/journal/MAR02 Issue/article01.htl

5. Arsham, H. 2010. Interactive education: impact of the Internet on learning and teaching. Retrieved October 2013 from http://home.ubalt.edu/ntsbarsh/interactive.htm

6. Bates, A. 2005.Technology, e-learning and distance education. London. Rutledge.

7. Claudia, M., Steil, A., and Todesco, J. 2004. Factors influencing the adoption of the internet as a teaching tool at foreign language schools. Computers and Education. 42, 353-374.

8. De Marsico, M., Sterbini, A., and Temperini, M. 2013. A Strategy to join adaptive and reputation-based socialcollaborative e-learning, through the zone of proximal development. International Journal of Distance Education Technologies (IJDET). 11, 12-31.

9. Garrison, D.R. 1997. Self-directed learning: toward a comprehensive model. Adult Education Quarterly, 48,1618.

10. Granger, C. A., Morbey, M. L., Lotherington, H., Owston, R. D., and Wideman, H. H. 2002. Factors contributing to teachers' successful implementation of IT. Journal of Computer Assisted Learning. 18, 480-488.

11. Henry, M. and Abala, A. 2009. E-learning research methods and approaches. Proceedings of the 1st Kuwait Conference on E-Services and E-Systems, Nov. 17-19, ACM Press, New York, pp: 1-4.

12. http://www.kcess.org/Papers-in-KCESS2009/a19-enry.pdf

13. Hofstede, Geert 2001. Culture's consequences: comparing values, behaviors, institutions, and organizations across nations (2nd Ed.). Thousand Oaks, CA. SAGE Publications.

14. Hunt, L.C., Jr. 1997. The Effect of Self-Selection, Interest, and Motivation upon Independent, instructional, and frustrational levels. Reading Teacher. 50, 278-282.

15. Issa, G. F., S.M. Hussain, and H. Al-Bahadilli, 2009. Economic efficiency analysis for informationtechnology in developing countries. Journal of Computer Science. 5, 751-759.

16. Kousha, K. 2004. Iran's national ICT education plan: an overview of the possibilities, problems and the programs. Proceedings of the 70th IFLA General Conference and Council on World Library and information Congress. Buenos Aires, Argentina, 1 -10.

17. Knowles, M. S. 1975. Self-directed learning: a guide for learners and teachers, Prentice Hall. Englewood Cliffs, New Jersey.

18. Laurillard, D. 1995. Multimedia and the changing experience of the learner. British Journal of Educational Technology. 26, 179-189.

19. Liaw, S. S. 2002. An Internet survey for perceptions of computer and World Wide Web: relationship, prediction, and difference. Computers in Human Behavior, 18(1), 17-35.

20. Liaw, S. S. (2004). Considerations for developing constructivist Web-based learning. International Journal of Instructional Media. 31, 309-321.

21. Lubis, M.A., S.R. Ariffin, T.A. Muhamad, M.S. Ibrahim andl.S. Wekke. 2009. The integration of ICT in the teaching and learning processes: A study on smart school of Malaysia. Proceedings of the 5thWSEAS/IASME International Conference on Education Technology. (ICET'09), National University of Malaysia, Malaysia.189197.

22. Muir-Herzig, R. G. 2004. Technology and its impact in the classroom. Computers and Education. 42, 111-131. 
23. Ong, C., and Lai, J. 2006. Gender differences in perceptions and relationships among dominants of e-learning acceptance. Computers in Human Behavior. 22, 816-829.

24. Omidnia, Masrom and Selamat.2011.Review of E-Learning and ICT Infrastructure in Developing Countries (Case Study of Iran), American Journal of Economics and Business Administration. 3, 120-125.

25. Rabiee, A. Nazarian, Z. Gharibshaeian, R. 2013. An Explanation for Internet Use Obstacles Concerning Elearning in Iran. International Review of Research in Open and Distance Learning 14, 361-377.

26. Rosenberg, M. 2001. E-Learning: Strategies for Delivering Knowledge in the Digital Age. New York: McGraw-Hill.

27. Rossett, A. and Sheldon, K. 2001. Beyond The Podium: Delivering Training and Performance to aDigital World.San Francisco: Jossey-Bass/Pfeiffer.

28. Rudenstam, O., A. 2012. Individualism vs. collectivism. Retrieved 2014, January 29, from https://blogs.law.harvard.edu/orudenstam/2012/10/05/individualism-vs-collectivism/

29. Saba, and Shearer, R. 1994. Verifying key theoretical concepts in a dynamic model of distance education. The American Journal of Distance Education. 8, 36-59

30. Tabatabaei, M. 2010. Evolution of distance education in Iran, Procedia, 2, 1043-1047.

31. Tavangarian D., Leypold M., Nölting K., Röser M., 2004. Is e-learning the Solution for Individual Learning? Journal of e-learning, 2, 273-280.

32. Umrani-Khan, F. and lyer, S. 2009. ELAM: A model foracceptance and use of e-learning by teachers andstudents. Proceedings of the 4th InternationalConference on E-Learning. July 16-17. University of Toronto, Canada, 1-25.

33. Wang, Y. S. 2003. Assessment of learner satisfaction with asynchronous electronic learning systems. Information andManagement, 41, 75-86.

34. Yaghoubi, J. Malek Mohammadi, I. Attaran, M. Iravani, and Gheidi, H. 2008. Virtual students' perception of elearning in Iran. The Turkish Online Journal of Educational Technology,7 , 159-173.

35. Passerini, K., and Granger, M. J. 2000. A development model for distance learning using the Internet. Computers and Education. 34, 1-15.

36. Spiro, R. J., Feltovich, P. J., Jacobson, M. J., and Coulson, D. K. 1995. Cognitive flexibility, constructivism, andhypertext: random access instruction for advanced knowledge acquisition in ill-structured domains. EducationalTechnology, 31, 24-33.

37. Warschauer, M., and Liaw, M. L. 2010. Emerging technologies in adult literacy and language education.Washington: National Institute for Literacy. Retrieved March 25, 2014 from: http://lincs.ed.gov/publications/pdf/technology paper 2010.pdf 